\title{
All Roads Lead to Burning Rome: Towards a Conceptual Model of IT Project Success
}

\author{
Jan Jöhnk ${ }^{1}$, Moritz Hartmann², and Nils Urbach ${ }^{3}$ \\ ${ }^{1}$ Project Group Business \& Information Systems Engineering of the Fraunhofer FIT, \\ University of Bayreuth, Bayreuth, Germany \\ jan.joehnkefit.fraunhofer.de \\ ${ }^{2}$ University of Bayreuth, Bayreuth, Germany \\ moritzhartmann1 @gmx. de \\ ${ }^{3}$ FIM Research Center, University of Bayreuth, Bayreuth, Germany \\ nils.urbachefim-rc.de
}

\begin{abstract}
Despite the maturity of IT project management in research and practice, a consistent understanding of IT project success (ITPS) and its constituents is still absent. The main objective of this paper is to ascertain the important constructs of ITPS and their interdependencies to overcome the absence of a comprehensive theoretical framework. Based on an initial literature search and six expert interviews, we built and validated a conceptual model consisting of critical success factors, contingency factors, and two success dimensions, whose interdependencies are illustrated by four propositions. Moreover, we extracted 67 critical success factors in ten categories from a structured literature review to harmonize the multitude of success factors stated in literature. The proposed model serves as a starting point for future research, which should focus on the detailed quantitative-empirical investigation of the cause-effect relationships and the contingency factors to validate our propositions and provide a generally accepted theory of ITPS.
\end{abstract}

Keywords: IT Project Management, IT Project Success, Critical Success Factors, Structured Literature Review, Interview Study.

\section{Introduction}

Faster technological development and increasingly customer-centered products force companies to strongly rely on information systems (IS) to tackle the emerging complexity. Yet, this complexity is also reflected in project management, as a considerable percentage of IT projects fail to achieve their objectives [1]. Reported failure rates vary between $56 \%$ and as high as $84 \%$ [2]. Furthermore, these project failures are not only critical due to cost and time overruns or quality shortcomings, but the consequences of some of these project failures can even threaten the entire company [3]. Despite these challenges for the successful implementation of IT projects, a comprehensive theory of IT project success seems to be omitted by research [4]. To the best of our knowledge, former research has often depicted detailed analyses of success 
factors but neglected their interrelation with success dimensions (e.g., [5]). In contrast, integrated approaches are rare and mostly scratch the surface in terms of success dimensions' and success factors' diversity (e.g., [6]). Moreover, definitions of relevant success dimensions vary, and success factors are rarely apt to be prioritized or compared $[2,7]$. From a practitioner's perspective, established project management standards such as the PMBOK, PRINCE2 or ICB also attempt to provide guidance on success dimensions and success factors. However, an agreed-upon understanding is necessary to form a joint basis for research and practice to act in concert. In the absence of such a common understanding, problems during the execution of projects arise, which eventually cause projects to fail. Consequently, although existing literature provides a multitude of potential ways and measures to increase the success of IT projects, too often all roads still lead to burning Rome. Hence, we identify two research gaps: First, the nomological ambiguity and deficient characterization of IT project success and its constituents. Second, the absence of a common understanding of relevant cause-effect relationships. Therefore, we pose the following research question: What constitutes IT project success and which factors influence IT project success?

Considering the extensive work in the project management domain, our research approach is threefold: First, we derive a conceptual model of IT project success from an initial literature search. Thereby, we distinguish between important success-related constructs of IT projects, i.e. IT project management success (ITPMS), IT project success (ITPS), as well as their measurement (i.e. success criteria) and their antecedents (i.e. critical success factors and contingency factors). Second, we gain a better understanding of our conceptual model of ITPS and associated practical challenges from six expert interviews, incrementally adjusting the model based on the expert's verdicts. Third, we address a specific problem from the initial literature search and our interviews, i.e. the inconsistent understanding of critical success factors. Building on a structured literature review of 41 papers, we identify 67 distinct critical success factors (CSFs) in ten categories. While we draw heavily on IT-specific literature and all of our interviews were conducted in this field, most of our findings might be transferable to project management in general. Yet, the results of this paper first and foremost address the management of IT projects. Our key contribution comprises a holistic categorization of CSFs to foster ITPS and advances towards a comprehensive conceptual model of ITPS. Our conceptual model of ITPS provides a sound basis for future research to elaborate on the cause-effect relationships, prioritize CSFs accordingly, and describe consequential actions for practice with a common understanding.

\section{$2 \quad$ Foundations}

Despite extensive research in this field, it is necessary to draw clear lines between the constituents of ITPS, owing to the vagueness of the terminology, the insufficient consideration of interrelations, and the absence of a common basis [8, 9]. Firstly, not all factors which affect success can be influenced from the organization executing the project. For instance, companies (and thus the projects) are subject to changes of the environment (e.g., economic, social, technological). A company can only react 
appropriately to these factors but cannot influence them directly [10]. Secondly, the influence of a success factor hinges on the selected success dimensions as well. Depending on the selected success criteria, a project can be considered successful or failed. Hence, we clarify the focal constructs and their interrelation in the following.

\subsection{Success Dimensions and Success Criteria}

Although determining the constituents of project success is complex and a common understanding of success criteria is missing [7, 10,11], it is important for a successful project execution to address the different perspectives and subjective construct definitions [12]. Extant research addresses the complexity of ITPS by adopting different success dimensions $[6,13]$. Likewise, we distinguish between ITPMS and ITPS as two independent success dimensions, each with its own success criteria $[4,14-16]$. This distinction bears two advantages: On the one hand, it appears not to be too complex for practical application. On the other hand, it is detailed enough to depict the different perspectives, internal as well as external. ITPMS focuses on the internal perspective of process efficiency [14]. With the project execution being interpreted as the process, the success can be measured according to the efficiency of project execution. Typical measures are based on the magical or iron triangle, with the success criteria time, cost and quality [17]. In contrast to the internal perspective of ITPMS, the success dimension ITPS depicts an external perspective of the project: Task outcomes (i.e., effectiveness and efficiency), psychological outcomes (i.e., satisfaction) and organizational outcomes (i.e., added value to business operations) [6,14]. The term external does not only refer to success criteria external to the project but also includes success criteria external to the company (e.g., shareholders or authorities) [18].

\subsection{Critical Success Factors}

Success factors are all inputs to the management system that have a direct or indirect positive influence on project success [19]. Under the premise that these characteristics or conditions are properly maintained and managed, they can have a significant influence on the success of a project [20]. Since project management literature lacks a unified success factor definition, we refer to the established term CSF [8, 21]. CSFs as defined by Bullen and Rockart [22], are the limited number of areas in which satisfactory results will ensure successful competitive performance for the individual, department, or organization. Literature often groups CSFs in distinct categories to bundle their respective influence on ITPS [10]. However, research lacks a common understanding of CSF categories, their particular importance and interdependencies [8].

\subsection{Contingency Factors}

In this context, it becomes apparent that there is a widespread lack in considering the relationships between the different terms. Along the lines of Belassi and Tukel [10], Howell et al. [11], and Hyväri [7], we distinguish a separate category of factors influencing the success of projects, i.e. contingency factors. According to established 
organizational contingency theory, an organization's effectiveness depends on its adaptation to its environment and hence its different external conditions [23]. Therefore, they are essential for describing the importance of adapting project management to the company surroundings and accounting for their influence on both, ITPMS and ITPS [11]. Although the project context is a direct consequence of project and organizational decision-making, a company might not be able to influence such contingency factors. Furthermore, these factors of project context are not unambiguous in their cause-effect relationships, which exacerbates their implementation and leaves them unsuitable for direct influence. Furthermore, depending on the contingency factor, CSFs may have a different effect or weighting, requiring them to be configured accordingly.

\section{Research Method}

The first step of our research process was an initial literature search based on the established frameworks of Webster and Watson [24] and vom Brocke et al. [25]. We used the following keywords to identify relevant papers in the project management domain without any restrictions of their publishing date: '[IT] project [management] success'; 'success factors [AND] project management'; '[IT] project [management] theory'. Drawing on the initial literature search, we extended the pool of papers through backward and forward search. Subsequently, the search results were screened for their relevance, i.e. a focus on CSFs, contingency factors, and/or success dimensions. Based on the literature analysis, we created an initial conceptual model of ITPS synthesizing our analysis of relevant work. The conceptual model comprises focal constructs as well as theoretical considerations and preliminary propositions for cause-effect relationships which we consolidated from the search results. The first author screened the pool of papers and discussed them with the third author to verify the emerging interrelations. We used this initial conceptual model of ITPS as the groundwork for our research and will present the revised final model in the Discussion section.

As second step in our research process, we conducted six expert interviews to corroborate our initial understanding of the conceptual model of ITPS. The results from our first research step revealed inconsistencies and no common understanding of focal constructs or potential cause-effect relationships for ITPS. Thus, our expert interviews aimed to provide a practical perspective regarding this nomological ambiguity and the associated challenges. We identified respondents (R1-R6) by expert sampling [26]. Potential interview partners had to have academic knowledge and/or practical experience in IT project management, irrespective of their specific role or contextual setting. Thereby, our sampling criteria included different perspectives which broadened our understanding of the initial conceptual model of ITPS. However, all interviewees had at least two years of practical project management experience (median: 9.5 years) allowing for hands-on, prudent insights. Three interviewees worked for IT consulting companies, two other interviewees were employed by manufacturing companies and one interviewee worked for a financial service institution in federal administration. Four interviewees held a position as a project manager, sometimes with a functional 
specialization, whereas the other two interviewees were members of the management board. Overall, the data gathering process followed the guidelines for interviews in IS research proposed by Myers and Newman [27]. The first author conducted and recorded the interviews, with transcription and anonymization following subsequently. The duration of the interviews ranged between 40 and 90 minutes, with all interviews but one having a duration of 60 minutes or more. Most of the interviews were carried out via telephone, while two respondents were interviewed face-to-face. The interviews followed a semi-structured interview guide with four sections, i.e. (1) introduction of the research team, research project, and interviewee, (2) an exploratory section regarding the interviewee's perspective on success dimensions and their antecedents, (3) a confirmative section regarding the interviewee's assessment of our initial conceptual model of ITPS, and (4) interview closure. Thereby, the interviews immediately built upon our insights from the first research step.

As third step in our research process, we conducted a structured literature review to follow up on a specific problem which had emerged from the preceding research steps, i.e. the inconsistent understanding of CSFs for ITPS. Drawing on our initial literature search and supported by our interviewees' assessment, this inconsistent understanding impedes a unified theory of ITPS and targeted decisions in project management practice. Therefore, we followed the procedure of Webster and Watson [24] to identify, structure, and summarize existing knowledge in this domain. We conducted a database search supplemented by two journals specifically dedicated to project management research for broad coverage. However, we also limited the search results to the period between 2000 and 2017 to achieve a manageable number of papers for analysis. Our search strings in this step specified the initial literature search from the first step to account for our better understanding during the research process. Thus, we included 'Traditional Project Management, 'Agile Project Management', and 'Agile Software Development' to systematically extend the search and account for the ongoing trend of agile methods' use [28]. This approach ensures a broad coverage of CSFs from different perspectives, accounts for insights from our expert interviews, and allows us to control for specifics of project management methods. Table 1 summarizes our approach for the structured literature search.

In total, we identified 299 papers, iteratively dismissing for duplicates (221 remaining), title (165), abstract (81), and full text (28). Subsequently, we identified 13 seminal literature review papers through a backward and forward search as well as from our first research step. We referred to the review guidelines of Bandara et al. [29] to ensure transparency and rigor of the additional papers. Moreover, we also used the search strings \{'Success Criteria'; 'Decision Criteria'; 'Adoption'\} in exchange for \{'Success Factor*'\} to substantiate our claims towards a comprehensive model of ITPS. From the resulting set of 41 eligible papers, the second author extracted 744 critical factors for ITPS. Next, the first two authors eliminated 85 factors owing to missing descriptions or non-conformity with our definition of CSFs, as well as 96 separate contingency factors. The two authors proceeded to harmonize the remaining CSFs to group similar factors concerning their meaning, irrespective from the specific wording. Ultimately, every CSF was supposed to be consistent, selfexplanatory, and directional. During eight independent coding rounds, we harmonized 
the CSFs and compared our allocations. We discussed the different wordings and our interpretation to adjust the CSFs to a similar level of abstraction and meaning. Finally, we synthesized the 744 extracted factors to 67 distinctive CSFs, grouped in ten categories, as basis for further analysis and corner stone of the revised conceptual model of ITPS.

Table 1. Overview of the applied search criteria during the structured literature review

\begin{tabular}{|c|c|}
\hline $\begin{array}{c}\text { Databases and } \\
\text { Outlets }\end{array}$ & $\begin{array}{c}\text { AIS Electronic Library, EBSCOhost, Google Scholar, ScienceDirect, Web } \\
\text { of Science, International Journal of Project Management, Journal of Project } \\
\text { Management }\end{array}$ \\
\hline Search String & $\begin{array}{c}\text { In \{'Title'; 'Abstract'; 'Keywords'\}: \{'Traditional Project Management'; 'Agile } \\
\text { Project Management'; 'Agile Software Development'\} AND \{'Success } \\
\text { Factor*'\} }\end{array}$ \\
\hline
\end{tabular}

\section{$4 \quad$ Results}

\subsection{Towards a Comprehensive Conceptual Model of IT Project Success}

Based on our three-step research process, we developed a conceptual model of ITPS. The model depicts our synthesis of current knowledge, accounting for the practical perspectives from our interviews and the specific context of IT projects. The model has four major components (CSFs, contingency factors, ITPMS, and ITPS). The causeeffect relationships between the respective constituents are represented by four preliminary propositions, which are backed by existing literature and our interviewees.

P1: Critical success factors have a positive effect on the success criteria of ITPMS.

According to this proposition, CSFs affect the success of projects concerning their efficiency in time, cost, and process quality [4, 14]. As the clarity of the model would suffer from the detailed representation of the individual causalities, the cause-effect relationships are consolidated for all CSF categories. Yet, it is important to notice that not all CSFs have a similar impact on the success criteria. In fact, the respective influence might vary significantly, and some success factors might not even influence ITPMS at all.

P2: Critical success factors have a positive effect on the success criteria of ITPS.

Similar to the impact of CSFs on ITPMs, they also influence ITPS. The cause-effect relationships between the respective CSF categories and the success dimensions of ITPS are again consolidated. In contrast to the process perspective of proposition P1, proposition P2 focuses on the outcome of projects and the effect of CSFs on these results $[4,14]$. Yet again, not all CSFs will influence ITPS necessarily.

P3: ITPMS has a positive influence on the success criteria of ITPS.

Proposition P3 suggests a partial, reinforcing mediation of ITPMS on ITPS, i.e. ITPMS is subordinate to ITPS [14]. This especially addresses the question whether a bad managed project can still have a successful outcome and vice versa. It is yet to determine how strong this causality and thus, the interdependency between the two constructs is. 
P4a-c: Contingency factors have a moderating effect on P1, P2 and P3.

Finally, the occurrence and management of contingency factors are a moderator for the cause-effect relationships of P1, P2, and P3. The appropriateness of a company's reaction on contingency factors can either reinforce or mitigate the effects of the CSFs or the effect of ITPMS on ITPS, respectively [6]. This is mainly due to changes of the project conditions or the organizational and environmental surroundings during project execution $[7,10]$.

However, during the initial literature search and our series of expert interviews, it became evident that the understanding of CSFs is inconsistent, which impedes the comparison of previous findings. Likewise, prioritization criteria and methods for CSFs vary between papers, further exacerbating this issue [2, 7]. Although our interviewees acknowledged the structure and interdependencies of our model, they frequently mentioned that "the level of abstraction is too high" to assess the CSFs specifically (cf. $\mathrm{R} 1$ ). Consequently, these issues prevent a uniform approach for practitioners. Therefore, the next section focuses on developing a common understanding of CSFs.

\subsection{Developing a Common Understanding of Critical Success Factors}

Our results of the structured literature review uncovered various approaches of research to categorize CSFs. However, there is still no consensus on an ideal approach or categorization perspective [30]. One typical perspective is built on different project stakeholders. This approach includes categories such as organization, people, technology, team, project, and customer [8, 31, 32]. From our perspective, such a categorization, though, would be too generic to be distinct and universally understandable. Hence, we chose the categories to align with activities and responsibilities instead. Nevertheless, the specifics of the stakeholder perspective remain apparent within the categories. Table 2 shows the ten categories and their CSFs from our structured literature review. In each category the CSFs are listed in descending order by the number of occurrences in the reviewed literature. This arrangement does not claim to provide a definitive ranking but rather serves for transparency and guidance for future research.

Collaboration. To work together efficiently, close cooperation within the project team and among the various project parties is essential [31, 33, 34]. In fact, one of our respondents considered the ability to work as a team superior to the level of competence in some cases, as he said, "if you have a good team, I don't think you need a team of absolute super professionals" (cf. R6). Beyond the project level, the same applies to the involved departments such as business and IT as well as external stakeholders including customers, users, and consultants [8, 32, 35]. Particularly in IT projects, the intensive and regular involvement of the customer and user is essential, "so in the end they are satisfied and not only thrown over the wall" (cf. R4). It requires an equal understanding and knowledge of the project goals, processes, and tasks as well as a strong relationship between business and IT to ensure that all project parties work together efficiently. 
Table 2. Final list of extracted and harmonized critical success factors

\begin{tabular}{|c|c|}
\hline Category & CSFs \\
\hline Collaboration & $\begin{array}{l}\text { High level of customer/user involvement; Continuous and regular } \\
\text { customer/user involvement; Good collaboration in project team; High level of } \\
\text { team mindedness; Strong partnership between business and IT; Interaction } \\
\text { with external partners }\end{array}$ \\
\hline Communication & $\begin{array}{l}\text { Effective communication; Face-to-face communication; Continuous and } \\
\text { regular project team communication; Formal and structured communication } \\
\text { procedures; Informal communication procedures }\end{array}$ \\
\hline Competence & $\begin{array}{l}\text { Project team knowledge/skills; High level of project manager leadership; } \\
\text { Project manager knowledge/skill; Customer/user experience; Customer/user } \\
\text { knowledge and skill; High performance by external partners; Project } \\
\text { manager experience; Project team experience }\end{array}$ \\
\hline Governance & $\begin{array}{l}\text { Status reporting and controlling; High level of formality and coordination in } \\
\text { project organizational structure; Clear assignment and perception of roles } \\
\text { and responsibilities; Clear and agreed success criteria; Apply qualitative and } \\
\text { quantitative performance metrics }\end{array}$ \\
\hline Management & $\begin{array}{l}\text { Ensure high level of top management support; Effective and integrated } \\
\text { change management; Ensure high level of common understanding and } \\
\text { stakeholder agreement; Ensure high level of risk management; Existence of } \\
\text { a project champion; Ensure high level of quality management }\end{array}$ \\
\hline $\begin{array}{l}\text { Methods and } \\
\text { principles }\end{array}$ & $\begin{array}{l}\text { Effective, efficient and appropriate project management method; High level } \\
\text { of project team autonomy; Establish learning as an integrated part of } \\
\text { organizational culture; Focus/knowledge on business objectives; High } \\
\text { familiarity with project management methods; Prioritization of project results; } \\
\text { Strong customer/user focus; Flexibility to overall changes in the project; } \\
\text { Useful documentation; Complete documentation; High level of } \\
\text { entrepreneurship and willingness to take risks; Pursue high level of simplicity } \\
\text { in design and processes }\end{array}$ \\
\hline $\begin{array}{l}\text { Motivation and } \\
\text { commitment }\end{array}$ & $\begin{array}{l}\text { Provide a project environment which motivates the team; Ensure a high level } \\
\text { of project team motivation; High customer/user commitment; Ensure high } \\
\text { level of project manager commitment }\end{array}$ \\
\hline Planning & $\begin{array}{l}\text { High invest in realistic/detailed project planning; Clear project } \\
\text { requirements/scope; Adequate resources; Variable project } \\
\text { requirements/scope; Budget management; Realistic project } \\
\text { requirements/scope; Fixed project requirements/scope; Structured planning } \\
\text { and project preparation }\end{array}$ \\
\hline $\begin{array}{l}\text { Staffing and } \\
\text { training }\end{array}$ & $\begin{array}{l}\text { Balanced team composition; Co-located project team; Provide sufficient level } \\
\text { of project team training; Provide sufficient level of customer/user training; } \\
\text { Small team size; Access and selection of external partners }\end{array}$ \\
\hline $\begin{array}{l}\text { Technology } \\
\text { and } \\
\text { development }\end{array}$ & $\begin{array}{l}\text { Select and provide the appropriate technology, PM tools and infrastructure } \\
\text { for project success; Effective and timely troubleshooting of bugs and crises; } \\
\text { Ensure effective test management; Knowledge and consideration of existing } \\
\text { legacy systems for reasons of compatibility; Alignment of business } \\
\text { processes and software development/implementation; Utilize pilot projects } \\
\text { and prototypes; Utilize standard solutions with a minimum degree of } \\
\text { customization }\end{array}$ \\
\hline
\end{tabular}

CSFs in each category sorted in descending order according to their number of occurrences

Communication. Similar to collaboration, communication is one of the most significant determinants influencing project stakeholders and their performance [31, 33, 36]. Based on respondents' findings, the reasons for this lie in the ability to "flag problems early" but also "to simply deal with people's expectations and reach out to them" (cf. R3). Considering the different forms and types of communication, we 
differentiate this category into effective, direct, continuous, formal, and informal communication, which are not exclusive but can be jointly present $[32,37,38]$.

Competence. This category contains all CSFs related to the experience, knowledge and skills of the most relevant project stakeholders [10, 36, 39]. While we define knowledge and skills as the ability to perform any task, experience emphasizes that the person already was involved in the relevant subject. This is exemplified and reinforced by the statements of the respondents who stated that "it helps if the project manager has the necessary experience, so that he can bring in his technical knowledge to solve the problems" (cf. R3) as well as that "if the project manager is more experienced, the chances are that the project will be successful" (cf. R6). As before, we distinguish between project team, manager, customer, and user for each of the CSFs.

Governance. In the context of IT projects, governance is an oversight function which defines all policies, processes, roles, and responsibilities providing the structure to which the project goals are set and the metrics to monitor the performance are determined [34, 40]. Therefore, this category includes activities concerning status reporting, level of formality, and coordination in the organizational structure as well as the clear assignment and perception of roles, responsibilities, success criteria, and performance metrics $[8,34,36]$. As the respondents pointed out, "it is rather easy to measure costs but more difficult to indicate a clear progress value to any time" (cf. R2). Accordingly, the main value of performance metrics lies in the fact that "only if I have them available at any time, I receive information at an early stage informing me that the project may no longer be running within the scope" (cf. R2).

Management. This category bundles CSFs that we consider to be important activities in the general project management phases from the organizational perspective [41]. In this context, our respondents emphasized the need to ensure the support of top management, as it is "one of the top factors that causes projects to fail" and thus is a "show stopper" (cf. R1; R2). Moreover, this category includes CSFs which refer to the existence of change, risk, stakeholder, and quality management $[34,36,38]$.

Methods and Principles. This category comprises CSFs addressing the successful execution of the chosen project management method [32, 42]. Hence, most of the included factors refer to different principles, values, and perceptions regarding learning, prioritization, documentation, flexibility, risk-avoidance, and simplicity. Thereby, these CSFs are distinct, but not always independent, of the respective project management method [35, 43]. Moreover, two CSFs focus on the general familiarity and usage of project management methods, as project management is "always strongly dependent on the organization" (cf. R3)

Motivation and Commitment. To achieve a high level of collaboration, it is necessary to develop and maintain the morale and motivation of each team member, manager, and customer during the project [5]. Moreover, this requires an environment which positively stimulates all project members [33, 44]. As our respondents emphasized, this is not only since "demotivation leads to poor project results", but also because "the employee establishes a mental association, for example via performancerelated compensation and the project and his or her activity in it" (cf. R1; R4). Accordingly, this category contains CSFs ensuring motivation and commitment for all stakeholders. 
Planning. Due to interdependency of the governance and planning category, it is difficult to distinguish clearly between their respective CSFs. However, in the context of our categorization, the planning category emphasizes the importance for detailed project planning combined with clear scope management and comprehensive budget management [36]. Thereby, issues of "requirements' clarity" as well as "adequate requirement analysis" were particularly stressed by several interviewees (cf. R2; R6). Moreover, a clear definition of the project status helps to avoid 'water melon' status reports, which appear to be "green on the outside but inside completely red" (cf. R2).

Staffing and Training. In order to execute a project successfully, a competent and motivated team is indispensable [5]. This requires the right selection, staffing, and training of employees. Especially in the context of IT projects, this encompasses the training of customers or users as well [36, 45]. In addition, one of our respondents admitted that "they always have insufficient time in projects but try to give their people enough time to explore the technologies" (cf. R3). Furthermore, this category comprises CSFs, which refer not only to a sufficient staffing process but also to a balanced team composition, proximity, training, and an appropriate team size [31, 32]. All these factors will eventually lead to a capable project team, customers, and users which is one of the most important aspects regarding project success [46].

Technology and Development. The last category includes all appropriate tools and technologies as well as the necessary infrastructure supporting the project and test management $[5,36]$. Moreover, useful testing and pilots can contribute to a project by "integrating the end user at an early stage" and helping them, "as they may not be able to address their requirements in time" (cf. R4). Particularly this category contains CSFs that are predominantly applicable to IT projects as they relate to software development and its processes.

\section{Discussion}

We synthesize our results from the initial literature search, the expert interviews, and the structured literature review in a comprehensive conceptual model of ITPS consisting of different CSF and contingency factor categories, ITPMS, and ITPS (cf. Figure 1). Thereby, the proposed model and its underlying cause-effect relationships constitute a promising starting point towards a holistic theory of ITPS.

The distinction of ITPMS and ITPS is in line with existing literature $[4,8]$ and was positively received by our interviewees. Nevertheless, our interviews emphasized the context specific and subjective perceptions of ITPMS and ITPS, which must be addressed. Thus, a quantitative-empirical validation and prioritization of the proposed criteria for ITPMS and ITPS are the next imperative steps to focus efforts in practice on the most important success criteria and further investigate their cause-effect relationships. Chua et al. [47] proposed a method based on the Analytical Hierarchy Process to rank CSFs according to the particular project goals in the construction industry. An adaptation to ITPMS and ITPS may provide decision makers with a sound basis for the prioritization of CSFs in IT projects. Apart from the four preliminary propositions, we found additional evidence for various other interdependencies (e.g., 
within and across CSF categories). Taking such interdependencies into account would add a considerable amount of complexity, which is why we decided to exclude them in the conceptual model. A detailed analysis of feedback loops within the conceptual model, similar to the case study research of Kansal [45], could foster the understanding for such interdependencies. Moreover, we like to point out that not all CSFs are equally important measured by their impact on ITPMS and ITPS. Previous research often addresses this notion by ranking or rating CSFs (e.g., [7, 10, 35]). However, this approach is deficient as it does not distinguish between different satisfactory levels of CSFs which our interviewees stated. On the one hand, necessary CSFs refer to a compulsory minimum to avoid project failure. On the other hand, sufficient CSFs are 'nice-to-have' and increase ITPMS and ITPS, but their absence will likely not cause the project to fail. This distinction of CSFs links to at least three other research streams, i.e. failure factors (e.g., [48-50]), Herzberg's two-factor-theory [51], and the KanoModel [52].

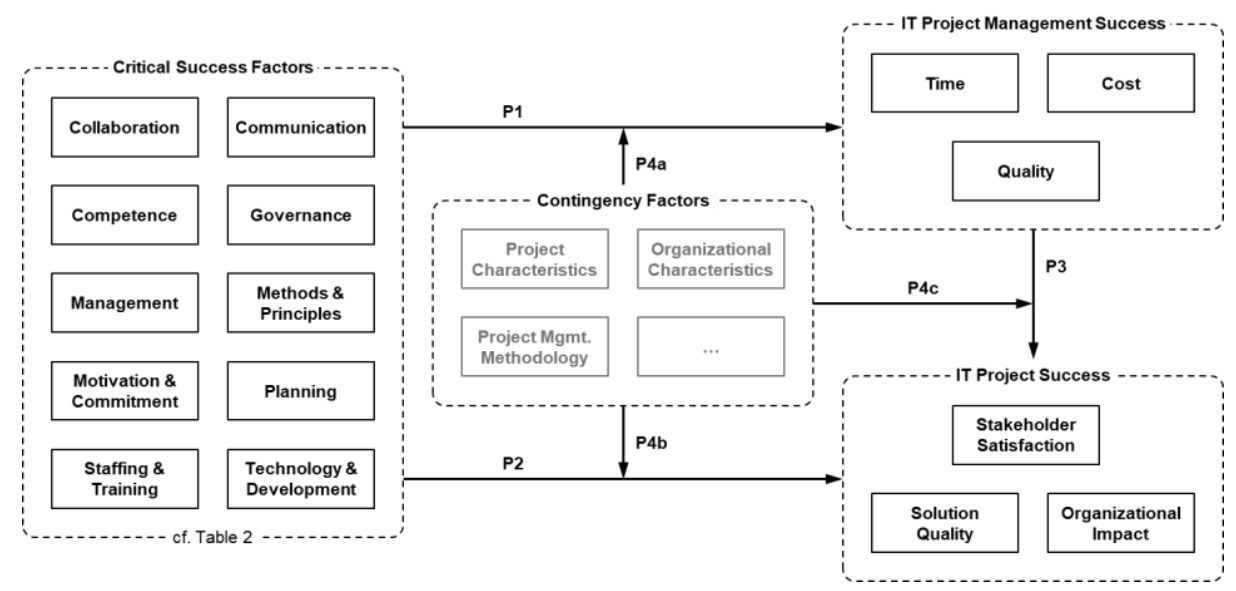

Figure 1. Conceptual model of IT project success

\subsection{Theoretical Contribution and Practical Implications}

Our paper provides novel insights for researchers and practitioners by synthesizing the vast body of knowledge and by providing a comprehensive conceptual model of ITPS. Thereby, our theoretical contribution is twofold. Firstly, we delineate the relevant terms to foster nomological clarity and mutual understanding in this research field. Especially the list of 67 CSFs in ten categories, which we harmonized from 744 existing factors, can provide a sound basis for future research in the field. Moreover, we distinguish not only ITPMS and ITPS, but CSFs and contingency factors as well, further increasing conceptual clarity. Secondly, the conceptual model with its nomological clarified constructs and preliminary propositions of cause-effect relationships provide a good starting point for further research to dive deeper into the complex interrelations of theses constructs. Our four preliminary propositions extend existing research which 
often focuses either primarily on CSFs (e.g., [5]) or adapts a narrow approach, lacking details on CSFs or success dimensions (e.g., [6]).

From a practical perspective, our research contributes to a better understanding by establishing an univocal characterization of ITPS and its constituents, eventually supporting practitioners in executing their projects more (often) successfully. Furthermore, our conceptual model with its four preliminary propositions may stimulate discussions of resource allocation and prioritization in project management decisions by shedding light on the questions "What constitutes a successful project and how can I achieve this?". This is especially useful for practitioners when they are experiencing trade-off decisions, i.e. decisions between limited resources, where an increased knowledge of the leveraging CSFs is valuable.

\subsection{Limitations and Future Research}

Our paper has some limitations considering its scope and research design, stimulating future research on the topic. Despite the academic knowledge and/or practical experience of the respondents, the results of our expert interviews build on a rather small sample of six interviewees. Thus, we cannot claim for generalizability, although their assessments strongly resembled our initial conceptual model. In particular, the lack of consideration of contingency factors and their influence must be underlined. Consequently, our findings are only indicators for the overall complexity of interdependencies between CSFs, contingency factors, ITPMS, and ITPS. Firstly, it is necessary to accomplish nomological clarity for the contingency factors as well before further investigating their influence. Secondly, future research should focus on the conceptualization and operationalization of the constructs, i.e. finding indicators and items to measure CSFs, contingency factors, ITPMS, and ITPS. The prioritization of the identified CSFs and the validation of our preliminary propositions based on a quantitative-empirical study would be meaningful next steps.

Such a quantitative-empirical validation of the proposed conceptual model lies outside the scope of this project. However, we are confident concerning our effort to consolidate the existing knowledge, providing a theoretical fundament for future research on these issues. Such a sound starting point bears the potential to facilitate future research activities. For instance, evidence for the influence of company size, company culture, project type or project size in our model is still scarce. Thereby, future research may extend our preliminary understanding and categorization of contingency factors, accounting for the project context. The ongoing trend towards agile project management methods is just one example that calls for a detailed investigation of CSFs depending on project context such as the chosen project management method $[8,42$, 53]. Finally, a large-scale survey based on our conceptual model of ITPS, may help to determine the varying interrelations of CSFs and contingency factors among each other as well as their influence on ITPMS on ITPS. 


\section{Conclusion}

Within this paper, we synthesized and extended existing research towards a common understanding of ITPS, its constituents, and interdependencies. Thereby, we described CSFs, contingency factors, and success dimensions (ITPMS and ITPS) in the context of IT projects. Four preliminary propositions denote the assumed causality between CSFs, contingency factors, ITPMS, and ITPS. The resulting conceptual model of ITPS provides a unified framework for analysis of ITPS and a starting point for future research. We corroborated the constructs and proposition of the conceptual model in six expert interviews and addressed the inconsistent understanding of CSFs with a structured literature review resulting in $67 \mathrm{CSFs}$, grouped in ten categories. In conclusion, our work contributes to fostering a holistic and joint theory of ITPS.

\section{References}

1. Xia, W., Lee, G.: Complexity of Information Systems Development Projects: Conceptualization and Measurement Development. Journal of Management Information Systems 22, 45-83 (2005)

2. Basten, D., Pankratz, O., Joosten, D.: Assessing the Assessors - An Overview and Evaluation of IT Project Success Reports. In: 21st European Conference on Information Systems (ECIS), pp. 1-12 (2013)

3. Bloch, M., Blumberg, S. and Laartz, J.: Delivering large-scale IT projects on time, on budget, and on value, http://www.mckinsey.com/insights/business_techn ology/delivering_large-scale_it_projects_on_time_on_budget_and_on_value

4. Basten, D., Pankratz, O.: Customer Satisfaction in IS Projects: Assessing the Role of Process and Product Performance. Communications of the Association for Information Systems 37, 430-447 (2015)

5. Finney, S., Corbett, M.: ERP implementation. A compilation and analysis of critical success factors. Business Process Mgmt Journal 13, 329-347 (2007)

6. Aladwani, A.M.: An Integrated Performance Model of Information Systems Projects. Journal of Management Information Systems 19, 185-210 (2002)

7. Hyväri, I.: Success of Projects in Different Organizational Conditions. Project Management Journal 37, 31-41 (2006)

8. Ahimbisibwe, A., Cavana, R.Y., Daellenbach, U.: A contingency fit model of critical success factors for software development projects. Journal of Ent Info Management 28, 7 33 (2015)

9. Schmidt, R., Lyytinen, K., Keil, M., Cule, P.: Identifying Software Project Risks: An International Delphi Study. Journal of Management Information Systems 17, 5-36 (2001)

10. Belassi, W., Tukel, O.I.: A new framework for determining critical success/failure factors in projects. International Journal of Project Management 14, 141-151 (1996)

11. Howell, D., Windahl, C., Seidel, R.: A project contingency framework based on uncertainty and its consequences. International Journal of Project Management 28, 256-264 (2010)

12. Wateridge, J.: IT projects: a basis for success. International Journal of Project Management 13, 169-172 (1995)

13. Bannerman, P.L., Thorogood, A.: Celebrating IT Projects Success: A Multi-Domain Analysis. In: 45th Hawaii International Conference on System Sciences (HICSS), pp. 48744883 (2012) 
14. Baccarini, D.: The Logical Framework Method for Defining Project Success. Project Management Journal 30, 25-32 (1999)

15. Collins, A., Baccarini, D.: Project Success - A Survey. J. Construct. Res. 5, 211-231 (2004)

16. McLeod, L., Doolin, B., MacDonell, S.G.: A Perspective-Based Understanding of Project Success. Proj Mgmt Jrnl 43, 68-86 (2012)

17. Atkinson, R.: Project management: cost, time and quality, two best guesses and a phenomenon, its time to accept other success criteria. International Journal of Project Management 17, 337-342 (1999)

18. Gemünden, H.G., Salomo, S., Krieger, A.: The influence of project autonomy on project success. International Journal of Project Management 23, 366-373 (2005)

19. Prabhakar, G.P.: What is Project Success: A Literature Review. IJBM 3 (2009)

20. Milosevic, D., Patanakul, P.: Standardized project management may increase development projects success. International Journal of Project Management 23, 181-192 (2005)

21. Lim, C.S., Mohamed, M.Z.: Criteria of project success: an exploratory re-examination. International Journal of Project Management 17, 243-248 (1999)

22. Bullen, C.V., Rockart, J.F.: A primer on critical success factors. Center for Information Systems Research, Sloan School of Management, Massachusetts Institute of Technology (1981)

23. Hanisch, B., Wald, A.: A Bibliometric View on the Use of Contingency Theory in Project Management Research. Project Management Journal 43, 4-23 (2012)

24. Webster, J., Watson, R.T.: Analyzing the Past to Prepare for the Future: Writing a Literature Review. MIS Quarterly 26, 13-23 (2002)

25. vom Brocke, J., Simons, A., Riemer, K., Niehaves, B., Plattfault, R., Cleven, A.: Standing on the Shoulders of Giants: Challenges and Recommendations of Literature Search in Information Systems Research. Communications of the Association for Information Systems 37, 205-224 (2015)

26. Bhattacherjee, A.: Social Science Research: Principles, Methods, and Practices. University of South Florida (2012)

27. Myers, M.D., Newman, M.: The qualitative interview in IS research. Examining the craft. Information and Organization 17, 2-26 (2007)

28. Hummel, M.: State-of-the-Art: A Systematic Literature Review on Agile Information Systems Development. In: 47th Hawaii International Conference on System Sciences (HICSS), pp. 4712-4721 (2014)

29. Bandara, W., Furtmueller, E., Gorbacheva, E., Miskon, S., Beekhuyzen, J.: Achieving Rigor in Literature Reviews: Insights from Qualitative Data Analysis and Tool-Support. Communications of the Association for Information Systems 37, 154-204 (2018)

30. Fortune, J., White, D.: Framing of project critical success factors by a systems model. International Journal of Project Management 24, 53-65 (2006)

31. Hummel, M., Epp, A.: Success Factors of Agile Information Systems Development: A Qualitative Study. In: 48th Hawaii International Conference on System Sciences (HICSS), pp. 5045-5054 (2015)

32. Misra, S.C., Kumar, V., Kumar, U.: Success Factors of Agile Software Development. Software engineering research and practice, 233-239 (2006)

33. Avital, M.: Reexamining Information Systems Success through the Information Technology Professionals Perspective. In: 11th European Conference on Information Systems (ECIS), pp. 1-16 (2003)

34. Taherdoost, H., Keshavarzsaleh, A.: How to Lead to Sustainable and Successful IT Project Management? Propose 5Ps Guideline. International Journal of Advanced Computer Science and Information Technology 4, 14-37 (2015) 
35. Karlsen, J.T., Andersen, J., Birkely, L.S., Odegard, E.: An empirical study of critical success factors in IT projects. International Journal of Management and Enterprise Development 3, 297-311 (2006)

36. Nasir, H.N., Sahibuddin, S.: Addressing a critical success factor for software projects: A multi-round Delphi study of TSP. International Journal of Physical Sciences, 1213-1232 (2011)

37. Hummel, M., Rosenkranz, C., Holten, R.: The Role of Communication in Agile Systems Development. Bus Inf Syst Eng 5, 343-355 (2013)

38. Imtiaz, M.A., Al-Mudhary, A.S., Mirhashemi, M.T., Ibrahim, R.: Critical Success Factors of Information Technology Projects. International Journal of Social, Education, Economics and Management Engineering 7, 1870-1874 (2013)

39. Serrador, P., Pinto, J.K.: Does Agile work? - A quantitative analysis of agile project success. International Journal of Project Management 33, 1040-1051 (2015)

40. Müller, R.: Project Governance. The European Journal for the Informatics Professional 12 (2011)

41. Duncan, W.R.: The Process of Project Management. Project Management Journal, 5-10 (1993)

42. Chow, T., Cao, D.-B.: A survey study of critical success factors in agile software projects. Journal of Systems and Software 81, 961-971 (2008)

43. El Hameed, T.A., Latif, M.A.E., Kholief, S.: Identify and Classify Critical Success Factor of Agile Software Development Methodology Using Mind Map. ijacsa 7, 83-92 (2016)

44. Stankovic, D., Nikolic, V., Djordjevic, M., Cao, D.-B.: A survey study of critical success factors in agile software projects in former Yugoslavia IT companies. Journal of Systems and Software 86, 1663-1678 (2013)

45. Kansal, V.: Systemic Analysis for Inter-Relation of Identified Critical Success Factors in Enterprise Systems Projects. CMR 3, 331-346 (2007)

46. Ciccotti, K.: The human factor in project management. In: PMI Global Congress (2014)

47. Chua, D.K.H., Kog, Y.C., Loh, P.K.: Critical Success Factors for Different Project Objectives. Journal of Construction Engineering and Management 125, 142-150 (1999)

48. Ibrahim, R., Ayazi, E., Nasrmalek, S., Nakhat, S.: An Investigation of Critical Failure Factors In Information Technology Projects. IOSR Journal of Business and Management 10, 87-92 (2013)

49. Shore, B.: Systematic biases and culture in project failures. Project Management Journal 39, 5-16 (2008)

50. Yeo, K.T.: Critical failure factors in information system projects. International Journal of Project Management 20, 241-246 (2002)

51. Herzberg, F.: One More Time: How Do You Motivate Employees? (reprint of 1968). Harvard Business Review 81, 87-96 (2003)

52. Kano, N., Seraku, N., Takahashi, F., Tsuji, S.: Attractive quality and must-be quality. Journal of the Japanese Society for Quality Control 14, 39-48 (1984)

53. Drechsler, A., Ahlemann, F.: Toward a General Theory of Agile Project Management - A Research Design. In: 23rd European Conference on Information Systems (ECIS), pp. 1-9 (2015) 